\title{
Vector abundance determines Trypanosoma prevalence in nestling blue tits
}

\author{
J. MARTÍNEZ-DE LA PUENTE ${ }^{1} * \dagger, J_{\text {. MARTÍNEZ }}^{2}$, J. RIVERO-DE-AGUILAR ${ }^{1}$, \\ S. DEL CERRO ${ }^{1}$ and S. MERINO ${ }^{1}$ \\ ${ }^{1}$ Departamento de Ecología Evolutiva, Museo Nacional de Ciencias Naturales (MNCN-CSIC), C\łosé Gutiérrez Abascal, \\ 2. E-28006, Madrid, Spain \\ ${ }^{2}$ Departamento de Microbiología y Parasitología, Universidad de Alcalá, Alcalá de Henares, Spain
}

\section{SUMMARY}

The effect of insect vectors on avian exposure to infection by pathogens remains poorly studied. Here, we used an insect repellent treatment to reduce the number of blood-sucking flying insects in blue tit Cyanistes caeruleus nests and examined its effect on nestling health status measured as body mass, nestling phytohaemagglutinin (PHA) response and blood parasite prevalence. We found that (i) the insect repellent treatment significantly reduced the number of blood-sucking flying insects in nests and (ii) the number of blood-sucking flying insects had a significant effect on the prevalence of the blood parasite Trypanosoma independently of the treatment. In addition, we found support for an adverse effect of parasite infections on nestling PHA response. Nestlings infected by Trypanosoma mounted a weaker response against PHA than non-parasitized ones. In addition, the number of blowflies in the nest was negatively associated with nestling PHA response. Overall, we found support for the hypothesis that blood-sucking flying insects attacking nestlings increase their exposure to parasite infections. Our results further substantiate the adverse effect of parasites on nestling condition.

Key words: biting midge Culicoides, black flies, Leucocytozoon, PHA response.

\section{INTRODUCTION}

Many parasites require blood-sucking vectors to be transmitted between vertebrate hosts. Factors including host abundance and immunocompetence may affect the epizootiology of vector-borne diseases, but vector abundance plays a prominent role in determining the exposure of a potential host to infections (Atkinson and Van Riper, 1991; Martínez-Abraín et al. 2004). Positive associations between pathogen infection and the abundance of vectors have been reported in different animal models including reptilians (Reardon and Norbury, 2004), mammals (Smith et al. 2005) and birds (Sol et al. 2000; Griffing et al. 2007). However, in spite of its importance in the understanding of the dynamics of diseases in avian populations, the direct relationship between the risk of infection by blood parasites and avian exposure to vectors has been rarely tested in the wild (Sol et al. 2000).

Most evidence supporting an association between the abundance of vectors and blood parasite

* Corresponding author. Departamento de Ecología de Humedales, Estación Biológica de Doñana (EBD-CSIC), C/ Américo Vespucio, s/n. E-41092, Seville, Spain. E-mail: jmp@ebd.csic.es

$\uparrow$ Present address: Departamento de Ecología de Humedales, Estación Biológica de Doñana (EBD-CSIC), C/ Américo Vespucio, s/n. E-41092. Seville, Spain. transmission to birds is indirect. For instance, the absence of suitable vectors might explain the low incidence of blood parasites in species living in marine/saline habitats (Super and van Riper, 1995; Figuerola, 1999; Mendes et al. 2005). Also, environmental characteristics around the nests, which may affect the abundance of vectors, seem to determine blood parasite prevalence in avian populations (Sánchez et al. 2007; Wood et al. 2007; Ortego and Cordero, 2010).

Nestlings from many species are constrained to the nest during the first developmental stages. Therefore, they have limited abilities to avoid ectoparasites once these have reached the nest, thus potentially increasing their exposure to pathogens (Merino, 2010). In addition to nest-dwelling parasites, a diversity of blood-sucking flying insects including mosquitoes, biting midges and black flies, bite on nestlings ('Tomás et al. 2008a; Votýpka et al. 2009). Attacks by blood-sucking flying insects may produce direct tissue damage, anaemia and immunological reactions against toxins and/or allergens contained in insect saliva (Hunter et al. 1997; Lehane, 2005). Moreover, they play a role as vectors of different blood parasites, potentially increasing the incidence of chronic diseases (Valkiūnas, 2005). The combined effect of both biting and infections by pathogens may impose important physiological costs on nestlings, reducing their general condition (Tomás et al. 2008b; 
Martínez-de la Puente et al. 2010) and survival probability (Hunter et al. 1997). Moreover, ectoparasite attacks during the nestling phase may induce longterm costs in survivors (Fitze et al. 2004).

In contrast to the well-studied effects of nestdwelling parasites on nestling fitness (Lehmann, 1993), there is scarce information about the effects of blood-sucking flying insects on nestling health status. Furthermore, the detection of infections by blood parasites in nestlings has an additional difficulty because, in some cases, pre-patent periods of infection are longer than or close to the period of nestling presence in the nest. Therefore, blood parasites are not always detectable in peripheral blood before nestlings leave the nest (Atkinson and Van Riper, 1991). However, some parasite genera, for example Leucocytozoon and Trypanosoma, are commonly found infecting nestlings (Fargallo and Merino, 2004; Arriero et al. 2008; Ortego and Cordero, 2010). These parasite genera have prepatent periods of about 5 days (Fallis and Bennett, 1961; Molyneux, 1973; but see Baker, 1956), which are shorter than those of other blood parasites (i.e. Haemoproteus and Plasmodium) commonly found infecting adults but rarely nestlings (Cosgrove et al. 2006).

Here, we experimentally modified the number of blood-sucking flying insects in blue tit, Cyanistes caeruleus, nests using an insect repellent. We studied the association between prevalence of infection by Trypanosoma and Leucocytozoon in nestlings and the abundance of blood-sucking flying insects in their nests. Trypanosoma and Leucocytozoon are the only blood parasites found infecting blue tit nestlings in this population (Fargallo and Merino, 2004). These parasite genera are transmitted by both biting midges (Ceratopogonidae: Culicoides) and black flies (Simuliidae) (Bennett, 1961; Miltgen and Landau, 1982; Morn et al. 1984; Votýpka and Svobodová, 2004; Valkiūnas, 2005), the only blood-sucking flying insects found in blue tit nests in the studied population (Tomás et al. 2008a). In addition, we studied the combined effect of the insect repellent treatment and blood parasite infection on nestling condition and phytohaemagglutinin (PHA) skin response, the last being a widely accepted indicator of avian immune status (Lochmiller et al. 1993; Hõrak et al. 1999; Martin et al. 2006) that does not produce any risk for the bird's health (see Merino et al. 1999).

\section{MATERIALS AND METHODS}

During the spring of 2009, we studied a blue tit population breeding in nest-boxes in a Pyrenean oak Quercus pyrenaica (Willd.) forest in central Spain $\left(40^{\circ} 53^{\prime} 74 \mathrm{~N}, 4^{\circ} 01^{\prime} \mathrm{W}, 1200 \mathrm{~m}\right.$ above sea level). All nest-boxes were emptied prior to bird occupation. Nests were periodically inspected to determine reproductive stages of birds.

\section{Treatments}

When nestlings were 3 days old, nests were assigned either to the insect repellent or to the control groups. Nests assigned to each treatment (control or insect repellent) were initially paired according to the number of nestlings and hatching date. Fumigation with the insect repellent was carried out when nestlings were 3, 7, 10 and 12 days old using the repellent 'Dixie Repellent Culicoides' (Química de Munguía S.A. - Quimunsa, Spain) containing water, $96^{\circ}$ alcohol $(35 \%)$, citronella $(3 \%)$ and ethyl butylacetylaminopropionate $(20 \%)$. The same methodology was employed in control nests using water instead of the repellent 'Dixie Repellent Culicoides'. Although the repellent is ready to use directly on the skin of animals, nestlings were extracted from nests prior to repellent application and immediately put back in their nest to avoid any potential detrimental effect on them. The same procedure was used in control nests. This repellent reduces the number of blood-sucking flying insects in nests without apparent negative effects on nestlings (Martínez-de la Puente et al. 2009a).

When nestlings were 13 days old, they were ringed, weighed with an electronic balance to the nearest $0 \cdot 1 \mathrm{~g}$ and their tarsus length measured with a dial calliper to the nearest $0.01 \mathrm{~mm}$. Subsequently, a drop of blood was taken from the brachial vein of each nestling and stored in an FTA card (Whatman, UK) for molecular identification of blood parasites.

\section{Measure of $\mathrm{PHA}$ response}

Nestlings were ringed at the age of 12 days. After that, a point on the wing web (patagium) of the right wing of each nestling was marked with permanent ink. Three measures were taken at that point with a digital 'spessimeter' with constant pressure (Mitutoyo Digimatic Thickness Gauge 547-313, Tokyo, Japan) to the nearest $0 \cdot 01 \mathrm{~mm}$ and the mean value calculated. Immediately after this measure was taken, nestlings were injected with $0.2 \mathrm{mg}$ of PHA dissolved in $0.04 \mathrm{~mL}$ of PBS in the right wing web point. After $24 \mathrm{~h}$, the web thickness was measured at the wing point following the procedure described above. Such measurements are highly repeatable (Saino et al. 1997; González et al. 1999; Moreno et al. 1999). The swelling response to PHA (wing web index) was calculated as the difference between pre- and postinjection measurements on the right wing web point (Smits et al. 1999). The response to PHA could not be measured in 9 nestlings from different broods.

\section{Molecular identification of blood parasite infections}

DNA was extracted from FTA cards following the protocol described by Martínez et al. (2009). Due to the low Leucocytozoon and Trypanosoma prevalence 
previously found in nestlings by microscopic methods in other field seasons, the molecular detection was carried out using qPCR in order to enhance the sensitivity. Two pairs of primers were designed and their specificities were checked by sequencing the amplicons obtained from different control samples.

Polymerase chain reactions used $20 \mu \mathrm{L}$ reaction volumes containing $20 \mathrm{ng}$ template DNA, $0 \cdot 12 \mu \mathrm{M}$ of each primer, and $10 \mu \mathrm{L}$ of Power SYBR ${ }^{\circledR}$ Green PCR Master Mix (Applied Biosystems, Foster City, CA, USA). Primers Try-F (5'-GGAGAGGGAGCC'TGAGAAATA-3') and Try-R (5'-ATGCAC'TAGGCACCGTCG-3') were designed to detect a fragment $(122 \mathrm{bp})$ of the $18 \mathrm{~S}$ rRNA gene from Trypanosoma, and primers qLeuF1 (3'-CCTTTATCATGGTATAGTGGT-5') and qLeuR1 (5'GC'TAAAGC'TACAAATGGG-5') were designed to detect a fragment $(233 \mathrm{bp})$ of the cytochrome $\mathrm{B}$ from Leucocytozoon. The reactions were cycled under the following conditions using the 7500 Fast RealTime PCR System (Applied Biosystems): $50{ }^{\circ} \mathrm{C}$ for $2 \mathrm{~min}, 95^{\circ} \mathrm{C}$ for $10 \mathrm{~min}, 40$ cycles at $95^{\circ} \mathrm{C}$ for $15 \mathrm{~s}$, $56^{\circ} \mathrm{C}$ for $30 \mathrm{~s}$, and $60^{\circ} \mathrm{C}$ for $30 \mathrm{~s}$. PCR products were detected monitoring the dissociation curve obtained. At least 1 positive control and 1 negative control were included per plate. DNA isolation of blood parasites failed for 5 broods (2 control and 3 insect repellent treatment broods) and 7 nestlings from different broods.

\section{Insect collection and quantification}

During the period between days 7 and 13 of nestling age, we captured blood-sucking flying insects using the method described and tested by Tomás et al. (2008a). In brief, the method consisted of placing inside and close to the roof of each nest-box a plastic Petri dish $\left(8.5 \mathrm{~cm}\right.$ diameter; $\left.56.7 \mathrm{~cm}^{2}\right)$ with a thinly spread layer of commercially available body gel-oil in which insects get trapped. On day 10, Petri dishes located on day 7 were replaced by new ones and maintained during another 3 days. We quantified the number of blood-sucking flying insects, both biting midges and black flies, per nest using an Olympus SZH stereomicroscope $(\times 10$ to $\times 64$ magnification $)$. The total number of blood-sucking flying insects in Petri dishes from each nest captured during the 6- day period was used in subsequent analyses. On day 20 or 21 after hatching, depending on when all nestlings had already fledged, nests were removed and nest material was teased apart over a white piece of paper to count the number of pupae of blowflies. Blowfly larvae of the dipteran Protocalliphora are commonly found in cavity nesters in the studied area (Moreno et al. 2009). However, because all flies could not be identified at the genus level, we cannot completely rule out the potential presence of a few Calliphora flies in the samples. The total number of blood-sucking flying insects and the number of pupae of blowflies were $\log _{10}(x+1)$ transformed to normalize their distribution. The number of blowflies was not quantified in one nest because a predator removed most of the nest material prior to nest collection.

\section{Statistical analysis}

Statistical analyses were conducted using Statistica (version 7.0, StatSoft, Inc. 2001), JMP and the GENMOD procedure in SAS 9.2 software (SAS Institute, Cary, NC, USA). Nestlings from 23 control and 20 fumigated nests were followed from the beginning of experimental treatment to fledging, although sample size varied between analyses because of the reasons described above. The GENMOD procedure was used to test for the effect of the fumigation treatment and the number of blood-sucking flying insects on the number of nestlings infected by each blood parasite (Trypanosoma and Leucocytozoon) with respect to uninfected nestlings in blue tit broods. To test for variables affecting the nestling immune system, we initially included in the model the PHA response of each nestling as dependent variable, the insect repellent treatment, the presence/ absence of Trypanosoma and the presence/absence of Leucocytozoon as factors, nest as a random factor and the number of blowflies and nestling body mass as continuous variables. The same procedure was used to test for the effect of the insect repellent treatment, the presence/absence of Trypanosoma and the presence/absence of Leucocytozoon, the number of blowflies and tarsus length on nestling body mass. Non-significant variables were removed from the final model using a backward stepwise procedure. The abundance of blowflies was included in the analyses in order to control for the potential negative effect of these parasites on nestling condition and PHA response (Hurtrez-Boussès et al. 1997; Puchala, 2004).

\section{RESULTS}

At the beginning of the experiment, there were no significant differences in hatching date $\left(F_{1,41}=0.92\right.$, $P=0.34)$ and brood size $\left(F_{1,41}=0.23, P=0.63\right)$ between nests subsequently assigned to fumigated and control groups. The number of blood-sucking flying insects was lower in insect repellent nests than in control nests after fumigation (fumigated nests: $9 \cdot 05 \pm 15 \cdot 76$, range: $0-62$, control nests: $71 \cdot 48 \pm 120 \cdot 60$, range: $\left.4-558 ; \quad F_{1,41}=24.08, \quad P<0.001\right)$; however, these insects were still present in most fumigated nests (14 of 20;70\%). The number of blowflies did not differ significantly between fumigated and control nests after fumigation (fumigated nests: $12 \cdot 15 \pm 11 \cdot 82$, range: $0-35$, control nests: $17 \cdot 55 \pm 18 \cdot 02$, range: $\left.0-62 ; F_{1,40}=0 \cdot 72, P=0 \cdot 40\right)$. 
Blood-sucking flying insects and blood parasite infections

A total of 278 nestlings from 38 broods (21 controls and 17 fumigated nests) were screened for blood parasite infections. The number of nestlings infected per brood ranged between 0 and 3. Trypanosoma infections were found in 6 nestlings from 2 fumigated and 4 control broods. Leucocytozoon infections were found in 11 nestlings from 1 fumigated and 6 control broods. We did not find any co-infected nestling. Because most nests were visited by blood-sucking flying insects, together with the fact that blood parasite prevalence could not be quantified for 3 insect repellent nests without biting flies, we conducted our analyses considering the number of bloodsucking flying insects together with the insect repellent treatment as the variable potentially explaining blood parasite prevalence. Using this approach, Trypanosoma infections were significantly and positively associated with the number of blood-sucking flying insects in the nest (treatment: $F_{1,36}=0 \cdot 21$, $P=0.64$; blood-sucking flying insects: $F_{1,36}=4 \cdot 22$, $P=0 \cdot 04)$. This was not the case for infections by Leucocytozoon (treatment: $F_{1,36}=0 \cdot 36, \quad P=0.55$; blood-sucking flying insects: $F_{1,36}=0 \cdot 53, P=0 \cdot 46$ ).

\section{Effects on nestling body mass and health status}

Nestling body mass was not significantly affected by any of the independent variables included in the model with the exception of tarsus length (data not shown). However, the PHA response was negatively associated with infections by Trypanosoma (Fig. 1, $\left.F_{1,223}=4 \cdot 79, P=0.03\right)$ and the number of blowflies (Fig. 2, $F_{1,223}=4.67, P=0.03$ ) and positively with nestling body mass $\left(F_{1,223}=5 \cdot 24, P=0 \cdot 02\right)$. The insect repellent treatment and infections by Leucocytozoon were not retained by the final model.

\section{DISCUSSION}

\section{Parasite prevalence in nestlings}

The prevalence of blood parasites infecting blue tit nestlings has previously been reported (Fargallo and Merino, 2004; Cosgrove, 2006; Arriero et al. 2008). Here, we found $29 \%$ of broods infected by Trypanosoma and/or Leucocytozoon parasites. A previous study in central Spain, by Arriero et al. (2008), found $16 \%$ and $13 \%$ of broods infected by Leucocytozoon in 2 consecutive years while only 1 nestling was found infected by Trypanosoma. Curiously, Fargallo and Merino (2004) found nestlings infected by Trypanosoma and Leucocytozoon in $80 \%$ and $100 \%$ of nests respectively, in the same blue tit population studied here. Discrepancies between studies could be due either to inter-annual differences in vector abundance in the area ('Tomás et al. 2008a),

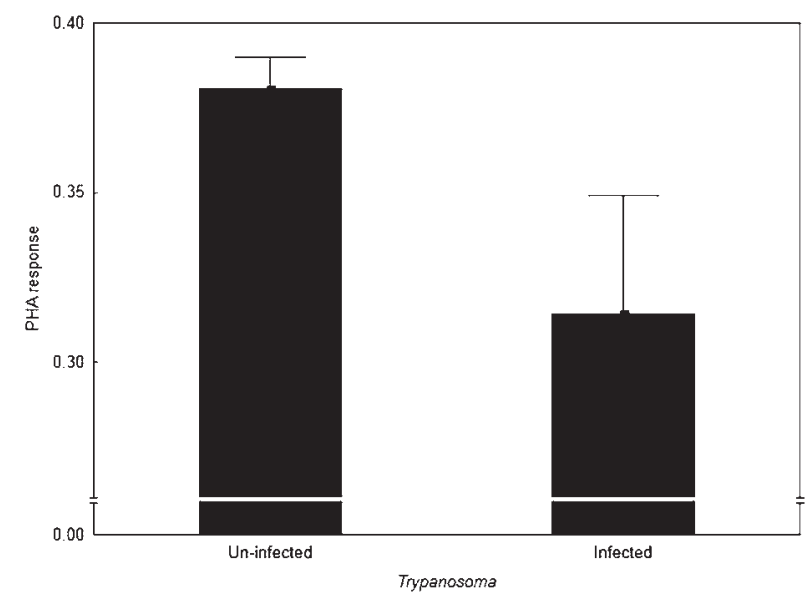

Fig. 1. Nestling PHA response $(\mathrm{mm})$ with respect to Trypanosoma infection status. Bars denote standard error.

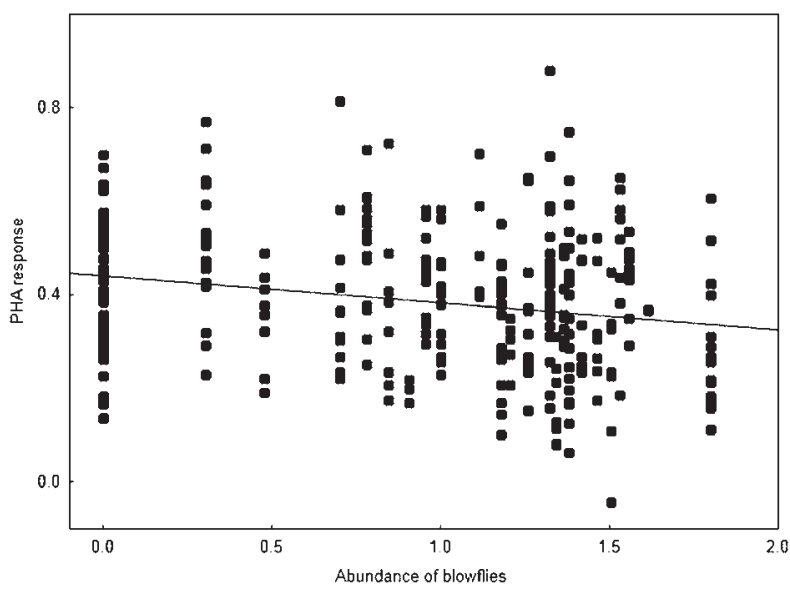

Fig. 2. Relationship between nestling PHA response $(\mathrm{mm})$ and the number of blowflies $\left(\log _{10} x+1\right)$ in the nest. Regression line is shown.

to differences in the immunological and/or nutritional state of nestlings (see Merino et al. 1996, $2000 a$ ), but also to the fact that Fargallo and Merino (2004) sampled nestlings 2 days older than those in this study. The probability of detecting parasites in the peripheral blood of nestlings may increase with nestling age because the time available for parasite transmission and development increases. Therefore, it is possible that we underestimated the prevalence of blood parasite infections in nestlings sampled at 13 days old. Nevertheless, the potential effect of undetected infections should render our results conservative because infected individuals would have been considered as uninfected.

\section{Blood parasite prevalence and blood-sucking flying insects}

The insect repellent treatment effectively reduced the number of blood-sucking flying insects in nests. Unexpectedly, this treatment did not reduce the prevalence of infection by blood parasites in nestlings. However, because the treatment did not 
completely eliminate blood-sucking flying insects from nests in most of the fumigated nests, nestlings were still exposed to blood parasite infections. In support of this possibility, the number of bloodsucking flying insects determined their infection status by Trypanosoma. The alternative, that more parasitized nestlings attracted more blood-sucking flying insects to their nest, is not supported by previous studies, in which low parasitized birds attracted more vectors than more parasitized ones (Tomás et al. 2008b; Martínez-de la Puente et al. 2009b; Lalubin et al. 2012). Sol et al. (2000) found good evidence supporting a role for vector abundance in determining the prevalence of infection by blood parasites in birds. These authors found that vector abundance correlated with the prevalence of infection by Haemoproteus and that the scarcity of vectors, and not other measured host traits, was the reason explaining the low prevalence of Haemoproteus (Sol et al. 2000). Our study on a different host-vector-blood parasite system agrees with their finding: the more vectors that visited the nest, the more likely nestlings were to be infected by blood parasites. Thus, factors affecting the number of blood-sucking flying insects in bird nests including brood size, nest temperature and weather conditions ('Tomás et al. 2008b; Martínezde la Puente et al . 2010) could be important determinants of the prevalence of infection by blood parasites in nestlings (see Fargallo and Merino, 2004).

\section{Parasites and $\mathrm{PHA}$ response}

Negative associations were found between Trypanosoma and blowfly infections and the PHA response in nestlings. Studies on captive house sparrows Passer domesticus reported that birds infected by blood parasites mounted a lower PHA response than uninfected birds (Navarro et al. 2003) and higher PHA responses were associated with a higher rate of recovery from parasite infections (González et al. 1999).

Because the relationships reported here between PHA response and parasite infections are not based on an experiment, we cannot identify the causality of these associations. First, it is possible that the lower PHA response found in infected nestlings is the consequence of parasite infections. The costs of infections may be multiple and diverse according to the parasite species involved. The costs may include metabolic changes affecting the allocation of resources that could otherwise be used for selfmaintenance (Møller, 1997; Merino et al. 2000b). Moreover, parasites are a source of physiological stress (Merino et al. 1998; Arriero et al. 2008; Martínez-de la Puente et al. 2011) and stress or the physiological responses to reduce the costs induced by stressful situations are immunosuppressant (Merino et al. 2001; Saino et al. 2003). Alternatively, a lower PHA response could indicate a nestling's susceptibility to infections. Nestlings may largely depend on their parents to mount an effective immunological response once parasites or their vectors reached the nests (Merino, 2010). Nutrition status plays a major role on the immune system of the nestling as supported by the positive association between the intensity of the PHA response and nestling condition (Saino et al. 1997; Navarro et al. 2003; this study) or food provisioning or availability (Lochmiller et al. 1993; Saino et al. 1997; HoiLeitner et al. 2001). Thus, a reduction in parental effort could reduce nestling condition and increase their susceptibility to infections (Merino et al. 1996). Under this assumption the relationship between the PHA response and parasite infections could be mediated by nestling condition. However, it was found that the associations between PHA response and parasite infections remained significant after controlling statistically for nestling body mass. Nevertheless, the scarcity of specific nutrients in nestling diet, such as protein content, could induce immunosuppression, thus increasing nestling exposure to parasites without detectable effects on body condition (Saino et al. 1997).

Finally, we did not find any significant effect of the insect repellent treatment on nestling body mass or PHA response after controlling for the effect of blood parasite infections. This suggests that blood parasites transmitted by blood-sucking flying insects, but not insect attacks, are mainly responsible for the detrimental effects on nestlings.

In conclusion, we found support for the fact that (i) the number of blood-sucking flying insects increases nestling exposure to blood-parasite infections and (ii) parasite infections adversely affect the nestling PHA response.

\section{ACKNOWLEDGEMENTS}

We thank Javier Donés (Director of Montes de Valsaín) for permission to work in the study area. The Junta de Castilla y León authorized the ringing and handling of birds. This study is a contribution to the research developed at the 'El Ventorrillo' field station. We thank J. Figuerola and L. Gangoso for their help with statistical analyses and two anonymous reviewers for helpful comments.

\section{FINANCIAL SUPPORT}

This study was funded by project CGL2009-09439. Josué Martínez-de la Puente is supported by a contract from the programme Funta para la Ampliación de Estudios (CSIC) co-financed by Fondo Social Europeo.

\section{REFERENCES}

Arriero, E., Moreno, J., Merino, S. and Martínez, J. (2008). Habitat effects on physiological stress response in nestling blue tits are mediated through parasitism. Physiological and Biochemical Zoology 81, 195-203. 
Atkinson, C. T. and van Riper, C., III (1991) Pathogenicity and epizootiology of avian haematozoa: Plasmodium, Leucocytozoan, and Haemoproteus. In Bird-Parasite Interactions: Ecology, Evolution and Behaviour (ed. Loye, J. E. and Zuk, M.), pp. 19-48. Oxford University Press, Oxford, UK.

Baker, J. R. (1956). Studies on Trypanosoma avium Danilewsky 1885. III. Life cycle in vertebrate and invertebrate hosts. Parasitology 46, 335-352. Bennett, G. F. (1961). On the specificity and transmission of some avian trypanosomes. Canadian Fournal of Zoology 39, 17-33.

Cosgrove, C. L., Knowles, S. C., Day, K. P. and Sheldon, B. C. (2006) No evidence for avian malaria infection during the nestling phase in a passerine bird. Fournal of Parasitology 92, 1302-1304

Fallis, A. M. and Bennett, G. F. (1961). Sporogony of Leucocytozoon and Haemoproteus in simuliids and ceratopogonids and a revised classification of the Haemosporidiida. Canadian Fournal of Zoology 39, 215-228.

Fargallo, J. A. and Merino, S. (2004). Clutch size and haemoparasite species richness in adult and nestling blue tits. Ecoscience 11, 168-174.

Figuerola, J. (1999). Effects of salinity on rates of infestation of waterbirds by haematozoa. Ecography 22, 681-685.

Fitze, P. S., Clobert, J. and Richner, H. (2004). Long-term life-history consequences of ectoparasite-modulated growth and development. Ecology 85, 2018-2026.

González, G., Sorci, G., Moller, A.P., Ninni, P., Haussy, C. and de Lope, F. (1999). Immunocompetence and condition-dependent sexua advertisement in male house sparrows (Passer domesticus). Fournal of Animal Ecology 68, 1225-1234.

Griffing, S. M., Kilpatrick, A. M., Clark, L. and Marra, P. P. (2007) Mosquito landing rates on nesting American robins (Turdus migratorius). Vector-borne and Zoonotic Diseases 7, 437-443.

Hoi-Leitner, M., Romero-Pujante, M., Hoi, H. and Pavlova, A. (2001) Food availability and immune capacity in serin (Serinus serinus) nestlings. Behavioral Ecology and Sociobiology 49, 333-339.

Hõrak, P., Tegelmann, L., Ots, I. and Møller, A. P. (1999). Immune function and survival of great tit nestlings in relation to growth conditions. Oecologia 121, 316-322.

Hunter, D. B., Rohner, C. and Currie, D. C. (1997). Mortality in fledgling great horned owls from black fly hematophaga and leucocytozoonosis. Fournal of Wildlife Diseases 33, 486-491.

Hurtrez-Boussès, S., Perret, P., Renaud, F. and Blondel, J. (1997). High blowfly parasitic loads affect breeding success in a Mediterranean population of blue tits. Oecologia 112, 514-517.

Lalubin, F., Bize, P., van Rooyen, J., Christe, P. and Glaizot, O. (2012). Potential evidence of parasite avoidance in an avian malarial vector. Animal Behaviour 84, 539-545.

Lehane, M. (2005). The Biology of Blood-sucking in Insects, 2nd Edn. Cambridge University Press, Cambridge, UK.

Lehmann, T. (1993). Ectoparasites: direct impact on host fitness. Parasitology Today 9, 8-13.

Lochmiller, R. L., Vestey, M. R. and Boren, J. C. (1993). Relationship between protein nutritional status and immunocompetence in northern bobwhite chicks. Auk 110, 503-510.

Martin, L. B., Han, P., Lewittes, J., Kuhlman, J. R., Klasing, K. C. and Wikelski, M. (2006). Phytohemagglutinin-induced skin swelling in birds: histological support for a classic immunoecological technique. Functional Ecology 20, 290-299.

Martínez, J., Martínez-de la Puente, J., Herrero, J., del Cerro, S., Lobato, E., Rivero-de Aguilar, J., Vásquez, R. A. and Merino, S. (2009). A restriction site to differentiate Plasmodium and Haemoproteus infections in birds: on the inefficiency of general primers for detection of mixed infections. Parasitology 136, 713-722.

Martínez-Abrain, A., Esparza, B. and Oro, D. (2004). Lack of blood parasites in bird species: does absence of blood parasite vectors explain it all? Ardeola 51, 225-232.

Martínez-de la Puente, J., Merino, S., Lobato, E., Riverode Aguilar, J., del Cerro, S. and Ruiz-de-Castañeda, R. (2009a) Testing the use of a citronella-based repellent as an effective method to reduce the prevalence and abundance of biting flies in avian nests. Parasitology Research 104, 1233-1236.

Martínez-de la Puente, J., Merino, S., Tomás, G., Moreno, J., Morales, J., Lobato, E., Talavera, S. and Sarto i Monteys, V. (2009b). Factors affecting Culicoides species composition and abundance in avian nests. Parasitology 136, 1033-1041.

Martínez-de la Puente, J., Merino, S., Lobato, E., Riverode Aguilar, J., del Cerro, S., Ruiz-de-Castañeda, R. and Moreno, J. (2010). Nest-climatic factors affect the abundance of biting flies and their effects on nestling condition. Acta Oecologica 36, 543-547.

Martínez-de la Puente, J., Merino, S., Tomás, G., Moreno, J., Morales, J., Lobato, E. and Martínez, J. (2011). Nest ectoparasites increase physiological stress in breeding birds: an experiment. Naturwissenschaften 98, 99-106.

Mendes, L., Piersma, T., Lecoq, M., Spaans, B. and Ricklefs, R. E. (2005). Disease limited distributions? Contrasts in the prevalence of avian malaria in shorebird species using marine and freshwater habitats. Oikos 109, 396-404

Merino, S. (2010). Immunocompetence and parasitism in nestlings from wild populations. Open Ornithology fournal 3, 27-32.

Merino, S., Potti, J. and Moreno, J. (1996). Maternal effort mediates the prevalence of trypanosomes in the offspring of a passerine bird. Proceedings of the National Academy of Sciences, USA 93, 5726-5730.

Merino, S., Martínez, J., Barbosa, A., Møller, A.P., de Lope, F., Pérez, J. and Rodríguez-Caabeiro, F. (1998). Increase in a heat shock protein from blood cells in response of nestling house martins (Delichon urbica) to parasitism: an experimental approach. Oecologia 116, 343-347.

Merino, S., Martínez, J., Møller, A.P., Sanabria, L., de Lope, F., Pérez, J. and Rodríguez-Caabeiro, F. (1999). Phytohaemagglutinin injection assay and physiological stress in nestling house martins. Animal Behaviour 58, 219-222.

Merino, S., Møller, A.P. and de Lope, F. (2000a). Seasonal changes in cell-mediated immunocompetence and mass gain in nestlings barn swallows: a parasite-mediated effect? Oikos 90, 327-332.

Merino, S., Moreno, J., Sanz, J. J. and Arriero, E. (2000b). Are avian blood parasites pathogenic in the wild? A medication experiment in blue tits (Parus caeruleus). Proceedings of the Royal Society of London, B 267, 2507-2510.

Merino, S., Martínez, J., Møller, A. P., Barbosa, A., de Lope, F. and Rodríguez-Caabeiro, F. (2001). Physiological and haematological consequences of a novel parasite on the red-rumped swallow Hirundo daurica. International Fournal for Parasitology 31, 1187-1193.

Miltgen, F. and Landau, I. (1982). Culicoides nubeculosus, an experimental vector of a new trypanosome from psittaciforms: Trypanosoma barkeri $\mathrm{n}$. $\mathrm{sp}$. Annales de Parasitologie Humaine et Comparee 57, 423-428. [Article in French]

Møller, A.P. (1997). Parasitism and the evolution of host life history. In Host-Parasite Evolution: General Principles and Avian Models (ed. Clayton, D. H. and Moore, J.), pp. 105-127. Oxford University Press, Oxford, UK.

Molyneux, D. H. (1973). Trypanosoma bouffardi of West African Ploceidae (Aves). Parasitology 66, 215-230.

Moreno, J., Sanz, J. J. and Arriero, E. (1999). Reproductive effort and T-lymphocyte cell-mediated immunocompetence in female pied flycatchers Ficedula hypoleuca. Proceedings of the Royal Society of London, B 266, 11051109 .

Moreno, J., Merino, S., Lobato, E., Ruiz-De-Castañeda, R. Martínez-de la Puente, J., del Cerro, S. and Rivero-de Aguilar, J. (2009). Nest-dwelling ectoparasites of two sympatric hole-nesting passerines in relation to nest composition: an experimental study. Ecoscience $\mathbf{1 6}$ 418-427.

Morn, T., Matsui, T., Iijima, T. and Fujinaga, F. (1984). Infectivity of Leucocytozoon caulleryi sporozoites developed in vitro and in vivo. International fournal for Parasitology 14, 135-139.

Navarro, C., Marzal, A., de Lope, F. and Møller, A. P. (2003). Dynamics of an immune response in house sparrows Passer domesticus in relation to time of day, body condition and blood parasite infection. Oikos 101, 291-298.

Ortego, J. and Cordero, P.J. (2010). Factors associated with the geographic distribution of leucocytozoa parasitizing nestling eagle owls (Bubo bubo): a local spatial-scale analysis. Conservation Genetics 11, 1479-1487.

Puchala, P. (2004). Detrimental effects of larval blow flies (Protocalliphora azurea) on nestlings and breeding success of tree sparrows (Passer montanus). Canadian Fournal of Zoology 82, 1285-1290.

Reardon, J. T. and Norbury, G. (2004). Ectoparasite and hemoparasite infection in a diverse temperate lizard assemblage at Macraes Flat, South Island, New Zealand. Fournal of Parasitology 90, 1274-1278.

Saino, N., Calza, S. and Møller, A.P. (1997). Immunocompetence of nestling barn swallows in relation to brood size and parental effort. Fournal of Animal Ecology 66, 827-836.

Saino, N., Suffritti, C., Martinelli, R., Rubolini, D. and Møller, A. P. (2003). Immune response covaries with corticosterone plasma levels under experimentally stressful conditions in nestling barn swallows (Hirundo rustica). Behavioral Ecology 14, 318-325.

Sánchez, S., Cuervo, J. J. and Moreno, E. (2007). Does habitat structure affect body condition of nestlings? A case study with woodland great tits Parus major. Acta Ornithologica 42, 200-204. 
Smith, A., Telfer, S., Burthe, S., Bennett, M. and Begon, M. (2005). Trypanosomes, fleas and field voles: ecological dynamics of a hostvector-parasite interaction. Parasitology 131, 355-365.

Smits, J. E., Bortolotti, G. R. and Tella, J. L. (1999). Simplifying the phytohemagglutinin skin testing technique in studies of avian immunocompetence. Functional Ecology 135, 567-572.

Sol, D., Jovani, R. and Torres, J. (2000). Geographical variation in blood parasites in feral pigeons: the role of vectors. Ecography 23, 307-314.

Super, P. E. and van Riper, C., III (1995). A comparison of avian hematozoan epizootiology in two California coastal scrub communities. Fournal of Wildife Diseases 31, 447-461.

Tomás, G., Merino, S., Martínez-de la Puente, J., Moreno, J., Morales, J. and Lobato, E. (2008a). A simple trapping method to estimate abundances of blood-sucking flying insects in avian nests. Animal Behaviour 75, 723-729.
Tomás, G., Merino, S., Martínez-de la Puente, J., Moreno, J., Morales, J. and Lobato, E. (2008b). Determinants of abundance and effects of blood-sucking flying insects in the nest of a hole-nesting bird. Oecologia 156, 305-312.

Valkiūnas, G. (2005). Avian Malaria Parasites and other Haemosporidia. CRC Press, Boca Raton, FL, USA.

Votýpka, J. and Svobodová, M. (2004). Trypanosoma avium: experimental transmission from black flies to canaries. Parasitology Research 92, 147-151. Votýpka, J., Synek, P. and Svobodová, M. (2009). Endophagy of biting midges attacking cavity-nesting birds. Medical and Veterinary Entomology 23, 277-280.

Wood, M. J., Cosgrove, C. L., Wilkin, T. A., Knowles, S. C., Day, K. P. and Sheldon, B. C. (2007). Within-population variation in prevalence and lineage distribution of avian malaria in blue tits, Cyanistes caeruleus. Molecular Ecology 16, 3263-3273. 